PREPARED FOR THE U.S. DEPARTMENT OF ENERGY, UNDER CONTRACT DE-AC02-76CH03073

PPPL-3587

PPPL-3587

UC-70

Stability and Confinement Properties
of Auxiliary Heated NSTX Discharges

by

J.E. Menard, R.E. Bell, C. Bourdelle, D.S. Darrow, E.D. Fredrickson, D.A. Gates, L.R. Grisham, S.M. Kaye, B.P. LeBlanc, R. Maingi, S.S. Medley, D. Mueller, F. Paoletti, S.A. Sabbagh, D. Stutman, D.W. Swain, J.R. Wilson, M.G. Bell, J.M. Bialek, C.E. Bush, J.C. Hosea, D.W. Johnson, R. Kaita, H.W. Kugel, R.J. Maqueda, M. Ono, Y-K.M. Peng, C.H. Skinner, V.A. Soukhanovskii, E.J. Synakowski, G. Taylor, G.A. Wurden, and S.J. Zweben

July 2001
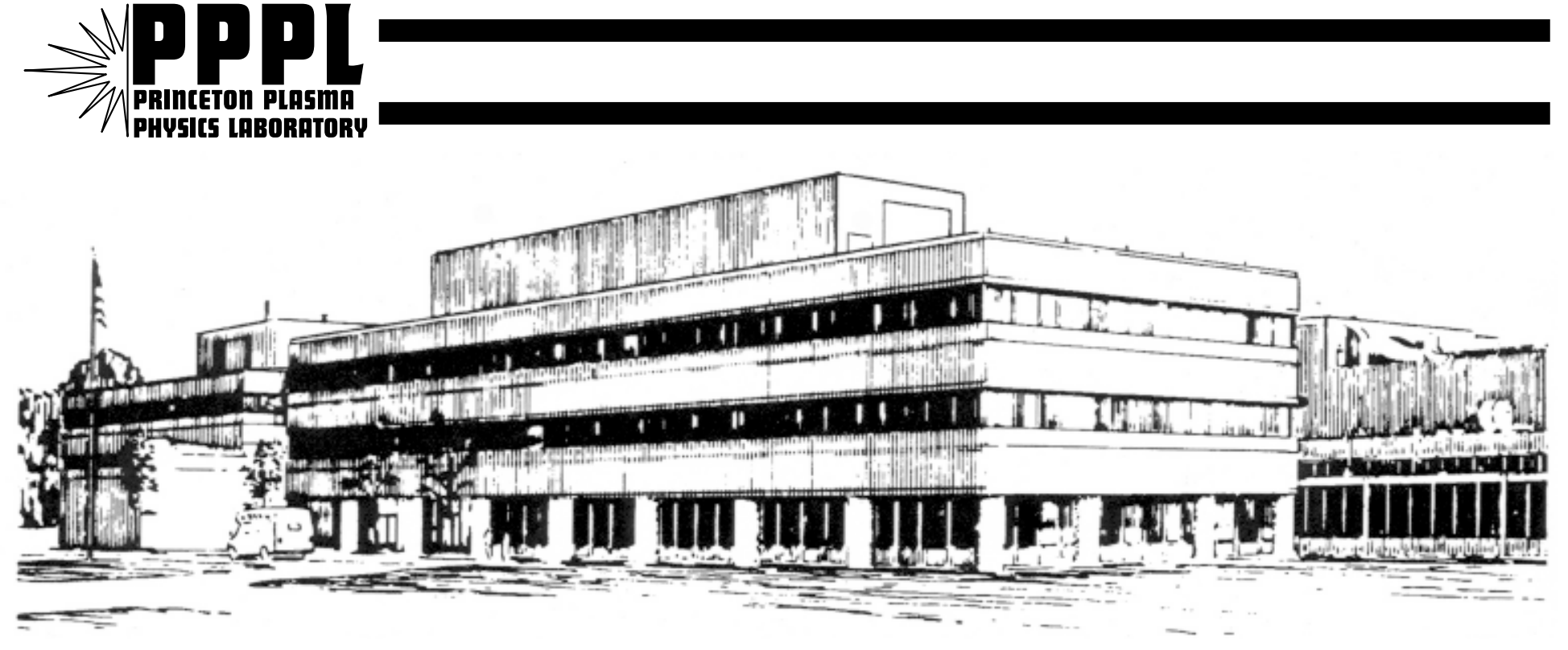

PRINCETON PLASMA PHYSICS LABORATORY PRINCETON UNIVERSITY, PRINCETON, NEW JERSEY 


\section{PPPL Reports Disclaimer}

This report was prepared as an account of work sponsored by an agency of the United States Government. Neither the United States Government nor any agency thereof, nor any of their employees, makes any warranty, express or implied, or assumes any legal liability or responsibility for the accuracy, completeness, or usefulness of any information, apparatus, product, or process disclosed, or represents that its use would not infringe privately owned rights. Reference herein to any specific commercial product, process, or service by trade name, trademark, manufacturer, or otherwise, does not necessarily constitute or imply its endorsement, recommendation, or favoring by the United States Government or any agency thereof. The views and opinions of authors expressed herein do not necessarily state or reflect those of the United States Government or any agency thereof.

\section{Availability}

This report is posted on the U.S. Department of Energy's Princeton Plasma Physics Laboratory Publications and Reports web site in Calendar Year 2001. The home page for PPPL Reports and Publications is: http://www.pppl.gov/pub_report/

DOE and DOE Contractors can obtain copies of this report from:

U.S. Department of Energy

Office of Scientific and Technical Information

DOE Technical Information Services (DTIS)

P.O. Box 62

Oak Ridge, TN 37831

Telephone: (865) 576-8401

Fax: (865) 576-5728

Email: reports@adonis.osti.gov

This report is available to the general public from:

National Technical Information Service

U.S. Department of Commerce

5285 Port Royal Road

Springfield, VA 22161

Telephone: 1-800-553-6847 or

(703) 605-6000

Fax: (703) 321-8547

Internet: http://www.ntis.gov/ordering.htm 


\title{
Stability and Confinement Properties of Auxiliary Heated NSTX Discharges
}

\author{
J.E. Menard ${ }^{1}$, R.E. Bell ${ }^{1}$, C. Bourdelle ${ }^{1}$, D.S. Darrow ${ }^{1}$, E.D. Fredrickson ${ }^{1}$, D.A. Gates ${ }^{1}$, \\ L.R. Grisham ${ }^{1}$, S.M. Kaye ${ }^{1}$, B.P. LeBlanc ${ }^{1}$, R. Maingi ${ }^{2}$, S.S. Medley ${ }^{1}$, D. Mueller ${ }^{1}$, \\ F. Paoletti ${ }^{3}$, S.A. Sabbagh ${ }^{3}$, D. Stutman ${ }^{4}$, D.W. Swain ${ }^{2}$, J.R. Wilson ${ }^{1}$, M.G. Bell ${ }^{1}$, \\ J.M. Bialek ${ }^{3}$, C.E. Bush ${ }^{2}$, J.C. Hosea ${ }^{1}$, D.W. Johnson ${ }^{1}$, R. Kaita ${ }^{1}$, H.W. Kugel ${ }^{1}$, \\ R.J. Maqueda ${ }^{5}$, M. Ono ${ }^{1}$, Y-K.M. Peng ${ }^{2}$, C.H. Skinner ${ }^{1}$, V.A. Soukhanovskii ${ }^{1}$, \\ E.J. Synakowski ${ }^{1}$, G. Taylor ${ }^{1}$, G.A. Wurden ${ }^{5}$, S.J. Zweben ${ }^{1}$ \\ ${ }^{1}$ Princeton Plasma Physics Laboratory, Princeton, NJ 08543-0451, USA \\ ${ }^{2}$ Oak Ridge National Laboratory, Oak Ridge, TN, USA \\ ${ }^{3}$ Columbia University, New York, NY, USA \\ ${ }^{4}$ Johns Hopkins University, Baltimore, MD, USA \\ ${ }^{5}$ Los Alamos National Laboratory, Los Alamos, NM, USA
}

\section{Introduction}

The National Spherical Torus Experiment (NSTX) is a spherical tokamak with nominal plasma major radius $\mathrm{R}_{0}=0.85 \mathrm{~m}$, minor radius $\mathrm{a}=0.66 \mathrm{~m}$, and aspect ratio $\mathrm{A}>1.28$. Typical discharge parameters are $\mathrm{I}_{\mathrm{P}}=0.7-1.4 \mathrm{MA}, \mathrm{B}_{\mathrm{t} 0}=0.25-0.45$ Tesla at $\mathrm{R}_{0}$, elongation $=1.7-2.2$, triangularity $0.3-0.5$, line-average electron density $\mathrm{n}_{\mathrm{e}}=2-5 \times 10^{19} \mathrm{~m}^{-3}, \mathrm{~T}_{\mathrm{e}}(0)=0.5-1.5 \mathrm{keV}$, and $\mathrm{T}_{\mathrm{i}}(0)=0.5-$ $2 \mathrm{keV}$. The NSTX auxiliary heating systems can routinely deliver $4.5 \mathrm{MW}$ of $80 \mathrm{keV}$ deuterium neutral beams and $3 \mathrm{MW}$ of $30 \mathrm{MHz}$ high-harmonic fast wave power. Kinetic profile diagnostics presently include a 10 channel, $30 \mathrm{~Hz}$ multi-pulse Thomson scattering system (MPTS), a 17 channel charge exchange recombination spectroscopy (CHERS) system, a 48 chord ultra-soft X-ray (USXR) array, and a 15 chord bolometry array. Initial experiments utilizing auxiliary heating on NSTX have focused on MHD stability limits, confinement trends, studying H-mode characteristics, and performing initial power balance calculations.

\section{Experimental Results}

\subsection{MHD Stability}

The spherical tokamak (ST) is expected to be stable to pressure-driven instabilities at high toroidal $\beta=\beta_{\mathrm{t} 0} \equiv 2 \mu_{0}\langle\mathrm{p}\rangle / \mathrm{B}_{\mathrm{t} 0}{ }^{2}$. Access to high $\beta$ is achieved by operating at high normalized current $=\mathrm{I}_{\mathrm{P}} / \mathrm{aB}_{\mathrm{t} 0}$ and derives from the Troyon [1] relation for the no-wall $\beta$-limit in tokamaks, $\beta_{\max } \leq \mathrm{C}_{\mathrm{T}} \mathrm{I}_{\mathrm{P}} / \mathrm{aB}_{\mathrm{t} 0}$ where $\mathrm{C}_{\mathrm{T}}$ is a constant. Key issues for the $\mathrm{ST}$ include (a) the determination of the maximum achievable $\beta_{\mathrm{N}} \equiv \beta(\%) \mathrm{a}(\mathrm{m}) \mathrm{B}_{\mathrm{t} 0}(\mathrm{~T}) / \mathrm{I}_{\mathrm{P}}(\mathrm{MA})$ and $(\mathrm{b})$ the definitions of $\beta$ and $\beta_{\mathrm{N}}$ (if any) which allow the Troyon relation to accurately apply to all tokamak aspect ratios. EFIT [2, 3] analysis of nearly 900 NSTX discharges with $\mathrm{I}_{\mathrm{P}}>0.5 \mathrm{MA}$ has been performed using external magnetic measurements only. Good agreement is found between EFIT and the measured diamagnetic flux, and the sawtooth inversion radius as determined from USXR tomography is in good agreement with the $\mathrm{q}=1$ radius as found by EFIT. 
The EFIT total stored energy tends to be $15-20 \mathrm{~kJ}$ larger than the sum of thermal plus fast particle stored energy based on measured $\mathrm{T}_{\mathrm{e}}, \mathrm{n}_{\mathrm{e}}$, and $\mathrm{T}_{\mathrm{i}}$ profiles and assuming classical confinement and thermalization of NBI ions. This results in a 10$15 \%$ uncertainty in the highest NSTX $\beta$ values. Figure 1 shows NSTX EFIT $\beta$ values at peak stored energy plotted versus $\mathrm{I}_{\mathrm{P}} / \mathrm{aB}_{\mathrm{t} 0}$. As seen in Figure 1a, NSTX has achieved $\beta_{N}=2-4$ over a range of $\mathrm{I}_{\mathrm{P}} / \mathrm{aB}_{\mathrm{t} 0}$ spanning 2-6. Thus far, the highest $\beta_{\mathrm{N}}$ values have been achieved at the lowest toroidal field $\mathrm{B}_{\mathrm{t} 0}=3 \mathrm{kG}$, although recently NSTX has achieved $\beta_{\mathrm{t} 0}=20 \%$ at $\mathrm{I}_{\mathrm{P}}=1.2 \mathrm{MA}$ and $\mathrm{B}_{\mathrm{t} 0}=3.5 \mathrm{kG}$. Figure $1 \mathrm{~b}$, shows the same NSTX data using the definition of $\beta$ originally used by Troyon [1]. As seen in the figure, using the volume average of $\mathrm{B}^{2}$ leads to $\beta$ values roughly a factor of 2 lower than the conventional tokamak definition. With this definition of $\beta,\left\langle\beta_{\mathrm{N}}\right\rangle \approx 2$ appears to better describe the $\beta$-limit of present NSTX discharges. Profile optimization will likely be required to reach the theoretical no-wall limit of $\left\langle\beta_{N}\right\rangle \approx 3$.

At the $\beta$-limit for the discharges of Figure 1, either rapid $\beta$ collapse or $\beta$ saturation is observed. The highest $\beta$ shots in NSTX routinely suffer rapid collapses, and inspection of the data in Figure 1 reveals that these discharges typically have $q(0)$ at or below 1 at collapse. For such discharges, ideal stability analysis shows that internal pressure-driven kink modes with toroidal mode numbers $n=1-2$ (sometimes higher) can simultaneously become unstable. Figure 2 a shows the frequency and toroidal mode number spectrum for a discharge with peak $\beta=20 \%$. This discharge suffers a rapid $\beta$ collapse at $\mathrm{t}=220 \mathrm{~ms}$ and shows a large $n=1$ (and smaller $n=2$ ) mode active at the collapse. Prior to this collapse, several other mode numbers are present throughout the discharge. As seen in Figure 2a, a large $80 \mathrm{kHz} n=1$ mode appears shortly after beam turn-on. The mode frequency scales roughly with the Alfven speed and is much higher than the initial plasma rotation frequency. Then, as $\mathrm{q}(0)$ approaches 1 near $\mathrm{t}=150 \mathrm{~ms}$, the $\mathrm{n}=1$

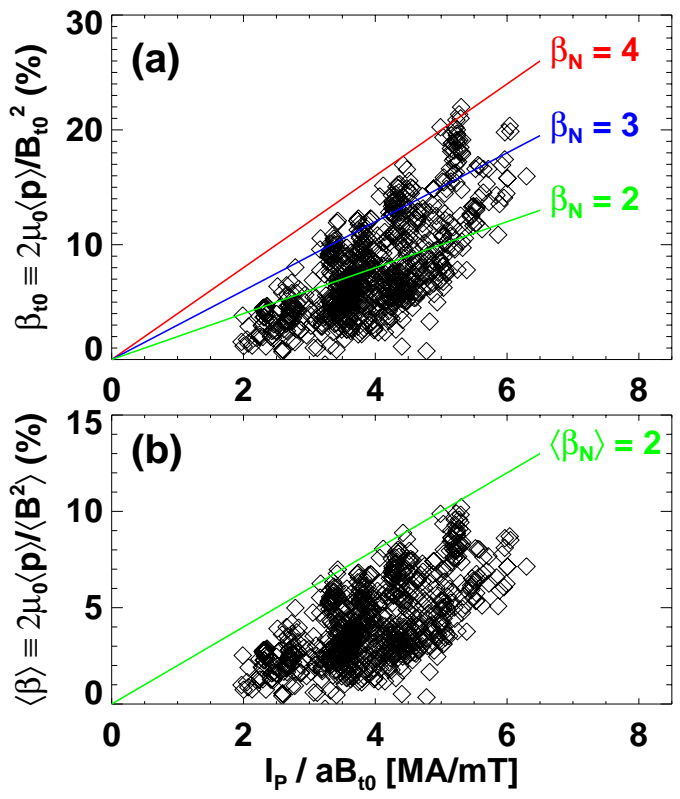

Figure 1. (a) Vacuum-toroidal beta and (b) volume-average beta versus I/aB for NSTX discharges with $I_{\mathrm{P}}>500 \mathrm{kA}$.
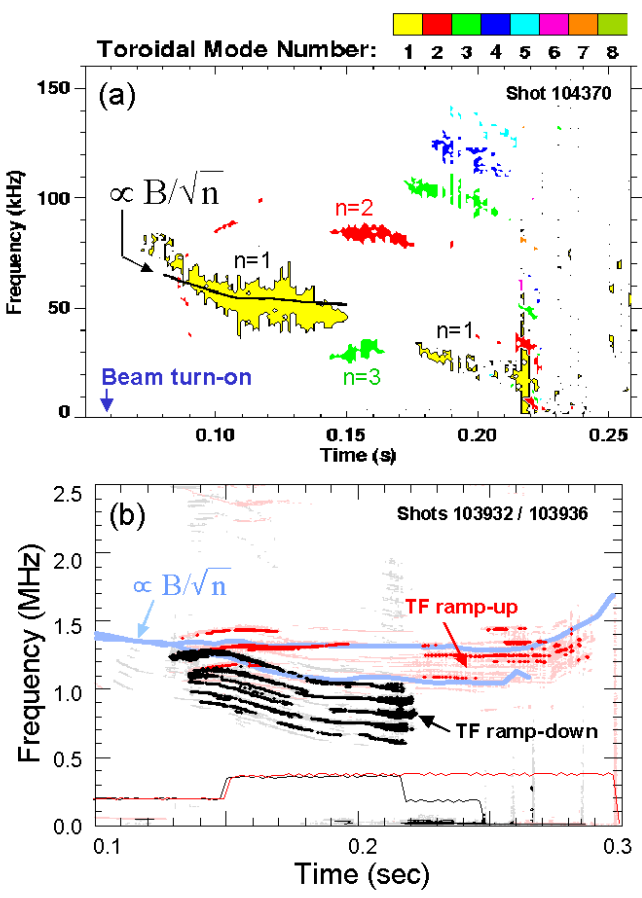

Figure 2. (a) Intermediate frequency $(0$ $150 \mathrm{kHz}$ ) $M H D$ activity for $a \beta=20 \%$ discharge and (b) $0.2-2 \mathrm{MHz} \mathrm{MHD}$ activity for lower $\beta$ discharges undergoing TF ramps. 

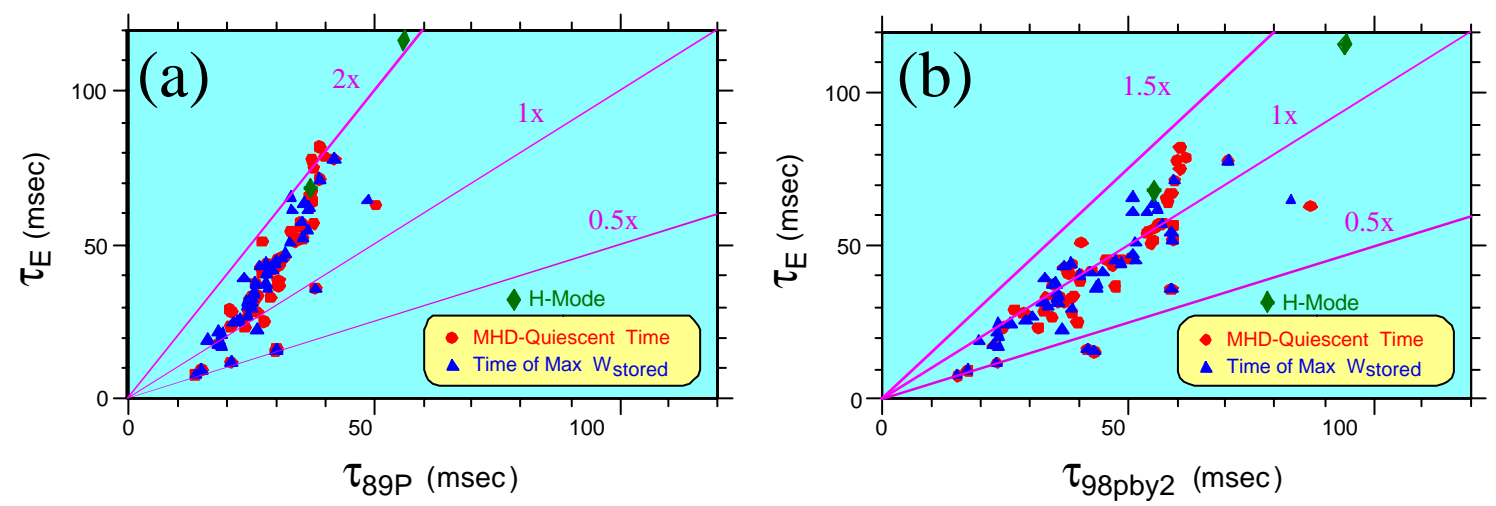

Figure 3. NSTX total energy confinement times compared to (a) ITER-89P and (b) 98pby2 scalings at peak stored energy (triangles) and MHD-quiescent time (circles).

mode disappears and $n=2$ and 3 modes appear at completely different frequencies. If these modes are Toroidal Alfven Eigenmodes (TAEs), continuum damping of the original $n=1$ mode by the presence of the 1/1 surface may explain this phenomena. Later, as $q(0)$ drops below 1 , the $\mathrm{n}=1$ (and higher) mode reappears and persists until the collapse. Not every NBI discharge has activity in this frequency range, and those that do have only minor fast ion losses when the modes are active. The highest $\beta_{\mathrm{P}}(\approx 0.4-0.5)$ discharges in NSTX typically have higher $\mathrm{q}(0)$ and more frequently exhibit $\beta$ saturation. Such discharges tend to have $n>1$ activity dominant during saturation. Neoclassical tearing modes are a very plausible cause of such saturation and are under active study.

Higher frequency NBI-driven MHD modes with $\mathrm{f}=0.5-2 \mathrm{MHz}$ have also been observed in NSTX. Figure $2 b$ shows the frequency spectra for two discharges - one with a toroidal field (TF) ramp-up, the second with a TF ramp-down. As seen in the figure, the mode frequency is observed to scale as the Alfven speed which indicates that the modes are plasma eigenmodes rather than energetic particle modes [4]. These modes exhibit most of the properties of Compressional Alfven Eigenmodes (CAE) [5] which can be be excited through a Dopplershifted perpendicular resonance with NBI fast ions at frequencies well below the ion cyclotron frequency where ion cyclotron and ion and electron Landau damping are weak. These modes cause no apparent fast ion loss, and in some circumstances are active when the lower-frequency TAE-like modes described above are also present.

\subsection{Confinement}

The achievement of high $\beta$ in NSTX has been greatly facilitated by good energy confinement even in non H-mode discharges. Figure 3a compares the total (thermal+beam) energy confinement times of select NSTX discharges to the ITER-89P L-mode scaling. As seen in the figure, $\mathrm{H}$-factors relative to $89 \mathrm{P}$ are in the range of 1-2 and increase as the confinement time increases. As expected, the highest confinement is achieved when MHD is not active (circles) or is weak. Figure 3b plots NSTX confinement against the 98pby2 H-mode scaling, and as seen in this figure, this scaling better matches NSTX for both H-mode and non H-mode discharges. Confinement times for two discharges with clear H-mode signatures are also plotted in the figure (green diamonds) and have $\mathrm{H} \approx 1.25$ relative to 98pby2. The spontaneous low-to- 
high (L-H) confinement mode transitions have only been observed in lower-single-null divertor discharges for $\mathrm{P}_{\mathrm{NBI}}>850 \mathrm{~kW}$ and $\mathrm{B}_{\mathrm{t} 0}=0.45$ Tesla. The $\mathrm{H}$-mode phase varies from $0.5-65 \mathrm{~ms}$ in duration and is typically terminated by peripheral MHD in the form of cold $\mathrm{m} / \mathrm{n}=2 / 1$ islands. The observation of clear H-mode transitions and profiles suggests that other high-confinement plasmas in NSTX are not transition-less H-modes. High-temperature bake-out of all NSTX graphite and control system upgrades are expected to further improve confinement in NSTX and hopefully allow easier access to H-mode.

Initial analysis of CHERS profiles obtained during NBI power step-ups shows that the $T_{i}$ profiles can be broader and hotter than the $\mathrm{T}_{\mathrm{e}}$ profiles. Figure $4 \mathrm{a}$ shows the ion (black) and electron (blue) temperatures for shot 104001 near $\mathrm{t}=290 \mathrm{~ms}$. This discharge has $\mathrm{I}_{\mathrm{P}}=1 \mathrm{MA}, \mathrm{B}_{\mathrm{t} 0}=4.5 \mathrm{kG}$, and achieves $\beta=9 \%$ and a peak stored energy of $150 \mathrm{~kJ}$. Figure $4 \mathrm{~b}$ shows that central rotation frequencies can approach $30 \mathrm{kHz}(200 \mathrm{~km} / \mathrm{s})$ and outboard plasma edge rotation velocities are also quite high $(40-50 \mathrm{~km} / \mathrm{s})$. Flat spots in the angular rotation profile appear to be correlated with MHD activity near mode-rational surfaces, particularly near $\mathrm{q}=2$. As seen in Figure $4 \mathrm{a}$, the central ion temperature is $\approx 2 \mathrm{keV}$ and significantly exceeds the electron temperature over most of the profile. The central electron density at $\mathrm{t}=297 \mathrm{~ms}$ is $4.3 \times 10^{19}$ $\mathrm{m}^{-3}$ and is sufficiently high that strong electron-ion thermal coupling is expected. In fact, this coupling

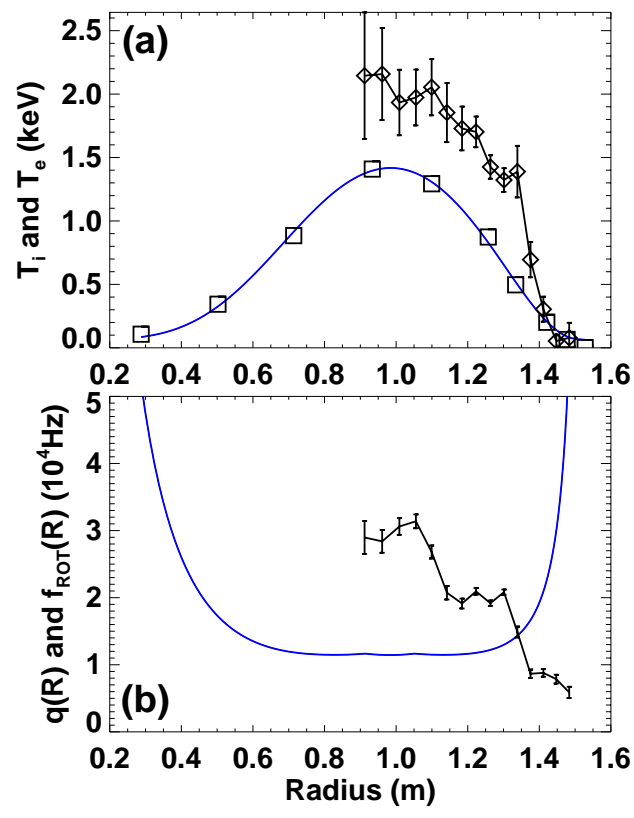

Figure 4. (a) Electron (blue) and ion temperature profiles and (b) safety factor (blue) and carbon rotation frequency profiles $(\div 10 \mathrm{kHz})$ for shot 104001 near $t=290 \mathrm{~ms}$. is computed (by TRANSP) to transfer 1.2MW from ions to electrons out of a total heating power of $1.75 \mathrm{MW}$ (1.5MW NBI). This results in a negative computed ion thermal conduction. Possible explanations of this situation include missing neoclassical corrections to the ionelectron coupling and anomalous ion heating [6]. Future experiments will attempt to better understand which plasma regimes exhibit this unusual behavior.

\section{Acknowledgments}

This work was supported by the United States Department of Energy under contract numbers DE-AC02-76CH03037 (PPPL), DE-AC05-00R22725 (ORNL), W-7405-ENG-36 (LANL) and grant numbers DE-FG02-99ER54524 (CU), DE-FG02-99ER54523 (JHU).

\section{References}

[1] F. Troyon et al., Plasma Phys. and Contr. Fus. 26, 209 (1984).

[2] L. L. Lao et al., Nucl. Fus. 25, 1611 (1985).

[3] S. A. Sabbagh et al., Nucl. Fus. (2001), accepted for publication.

[4] E. D. Fredrickson et al., to be submitted to Phys. Rev. Lett.

[5] N. Gorelenkov and C. Cheng, Nucl. Fus. 35, 1743 (1995).

[6] D. A. Gates, R. White, and N. Gorelenkov, submitted to Phys. Rev. Lett. 


\section{External Distribution}

Plasma Research Laboratory, Australian National University, Australia

Professor I.R. J ones, Flinders University, Australia

Professor J oão Canalle, Instituto de Fisica DEQ/IF - UERJ , Brazil

Mr. Gerson O. Ludwig, Instituto Nacional de Pesquisas, Brazil

Dr. P.H. Sakanaka, Instituto Fisica, Brazil

The Librarian, Culham Laboratory, England

Library, R61, Rutherford Appleton Laboratory, England

Mrs. S.A. Hutchinson, JET Library, England

Professor M.N. Bussac, Ecole Polytechnique, France

Librarian, Max-Planck-Institut für Plasmaphysik, Germany

J olan Moldvai, Reports Library, MTA KFKI-ATKI, Hungary

Dr. P. Kaw, Institute for Plasma Research, India

Ms. P.J . Pathak, Librarian, Insitute for Plasma Research, India

Ms. Clelia De Palo, Associazione EURATOM-ENEA, I taly

Dr. G. Grosso, Instituto di Fisica del Plasma, Italy

Librarian, Naka Fusion Research Establishment, J AERI, J apan

Library, Plasma Physics Laboratory, Kyoto University, J apan

Research Information Center, National Institute for Fusion Science, J apan

Dr. O. Mitarai, Kyushu Tokai University, J apan

Library, Academia Sinica, Institute of Plasma Physics, People's Republic of China

Shih-Tung Tsai, Institute of Physics, Chinese Academy of Sciences, People's Republic of China

Dr. S. Mirnov, TRINITI, Troitsk, Russian Federation, Russia

Dr. V.S. Strelkov, Kurchatov Institute, Russian Federation, Russia

Professor Peter Lukac, Katedra Fyziky Plazmy MFF UK, Mlynska dolina F-2, Komenskeho Univerzita, SK-842 15 Bratislava, Slovakia

Dr. G.S. Lee, Korea Basic Science Institute, South Korea

Mr. Dennis Bruggink, Fusion Library, University of Wisconsin, USA

Institute for Plasma Research, University of Maryland, USA

Librarian, Fusion Energy Division, Oak Ridge National Laboratory, USA

Librarian, Institute of Fusion Studies, University of Texas, USA

Librarian, Magnetic Fusion Program, Lawrence Livermore National Laboratory, USA

Library, General Atomics, USA

Plasma Physics Group, Fusion Energy Research Program, University of California at San Diego, USA

Plasma Physics Library, Columbia University, USA

Alkesh Punjabi, Center for Fusion Research and Training, Hampton University, USA

Dr. W.M. Stacey, Fusion Research Center, Georgia Institute of Technology, USA

Dr. J ohn Willis, U.S. Department of Energy, Office of Fusion Energy Sciences, USA

Mr. Paul H. Wright, Indianapolis, Indiana, USA 
The Princeton Plasma Physics Laboratory is operated by Princeton University under contract with the U.S. Department of Energy.

\author{
Information Services \\ Princeton Plasma Physics Laboratory \\ P.O. Box 451 \\ Princeton, NJ 08543
}

Phone: 609-243-2750

Fax: 609-243-2751

e-mail: pppl_info@pppl.gov

Internet Address: http://www.pppl.gov 